\title{
Onda corta vs. radio online. Radio Exterior de España en la era digital
}

Antonio Fernández Cuesta

Periodista de RNE

La irrupción de Internet y la aparición en los últimos años de dispositivos móviles como las tabletas y los teléfonos inteligentes está suponiendo una auténtica revolución en los medios de comunicación, y la radio no es ajena a esos cambios. Frente a lo que está ocurriendo con la prensa escrita, en el caso de la radio, Internet se ha convertido en un aliado que multiplica la oferta de emisoras de forma exponencial y ofrece unos servicios añadidos sumamente interesantes para el oyente, como los podcast, la radio a la carta y una mayor participación, a través de redes sociales, como Facebook y Twitter, por citar sólo algunas de las posibilidades.

El aumento del consumo de radio a través de Internet queda reflejado en un estudio de la Asociación para la Investigación de los Medios de Comunicación (AIMC), que refleja que más de 11 millones de españoles escuchan la radio a través de Internet cada mes. El informe también revela que la radio online añade más consumo al tiempo total de escucha de la radio tradicional. Los datos del último Estudio General de Medios de la AIMC avalan, en parte, la teoría de que Internet se ha convertido en un fenómeno potenciador de la radio como medio de comunicación. Según esta encuesta, la penetración de la radio en la sociedad española ha aumentado en los últimos cuatro años en más de ocho puntos, al pasar de un $53,1 \%$ en 2008 a un $61,9 \%$ en 2012, es decir, cada día más de veinticuatro millones de españoles escuchan alguna emisora. Conviene observar que ese periodo coincide en buena medida con el boom de Internet y la aparición de dispositivos móviles que facilitan la escucha. 
Como hemos comentado, Internet multiplica la oferta de emisoras a disposición de los oyentes. Entre esas nuevas opciones, queremos referirnos a Radio Exterior de España (REE), el canal internacional de Radio Nacional de España que en 2012 cumplió su 70 aniversario. Se da la circunstancia de que esta emisora no se podía escuchar en España hasta no hace mucho tiempo, porque su única vía de difusión era la onda corta (una banda de radiofrecuencias en la que emiten, entre otras, las emisoras de radio internacionales para transmitir su programación al mundo y las estaciones de radioaficionados). Por cuestiones técnicas - que no podemos entrar a detallar en este artículo-, la onda corta (OC) es capaz de llevar la señal a miles de kilómetros de distancia, pero en cambio no se puede escuchar en el entorno más cercano al punto desde el que se emite.

La OC convertía a la radio, a principios del siglo XX, en el primer medio de comunicación global, ya que permitía transmitir la información a cualquier punto del planeta de una forma muy rápida y relativamente sencilla. Las grandes potencias de la época se dieron cuenta del enorme potencial de la onda corta y pusieron en marcha las radios internacionales. Las más conocidas han sido el servicio mundial de noticias de la BBC Británica, Radio Francia Internacional, Radio Netherland, La Voz de América, la Voz de Rusia... Las iglesias también se percataron de la enorme capacidad de la onda corta para extender sus mensajes y, por ejemplo, Radio Vaticana transmite al mundo en esta banda en múltiples idiomas.

Las radios internacionales se utilizaron como potentes medios propagandísticos en los grandes conflictos bélicos, como la II Guerra Mundial. La Guerra Fría marcó un hito en el uso de la OC. «El telón de acero era un muro invisible que las ondas electromagnéticas cruzaban de lado y lado», como ha indicado Santiago García Gago en su Manual para Radialistas Analfatécnicos. España no fue ajena a ese proceso. En junio de 1941 comienza a emitir desde Moscú Radio España independiente, conocida también como Radio Pirenaica, una emisora creada por el Partido Comunista de España que acabó convertida en la voz de la esperanza antifranquista. Por su parte, en marzo de 1942 se oficializan las emisiones para el exterior de Radio Nacional. En sus comienzos, se utilizó como forma de propaganda por la dictadura franquista y posteriormente se convirtió en un apoyo para los millones de emigrantes que salieron de España a Europa y América. Radio Exterior de España es en la actualidad una radio internacional moderna que tiene, entre sus principales cometidos, difundir todo lo español en el amplio sentido de la palabra y también ser instrumento para que los españoles en el extranjero se sientan más cerca de su país. REE emite en la actualidad en diez idiomas y sus programas llegan a oyentes de los cinco continentes.

Con los satélites, la radio digital y, sobre todo, la generalización de Internet, el uso de la onda corta viene experimentando un descenso considerable sobre todo en algunas zonas como Norteamérica y Europa. Esto, unido a los elevados costes de transmisión a través de OC, y de mantener una programación en diversos idiomas ha llevado a algunas emisoras internacionales a poner fin a sus emisiones en onda corta para algunas regiones o recortar su programación. Este 
es el caso de Radio Canadá Internacional, Radio Netherland, Radio Vaticano y hasta la BBC, que en 2011 puso fin a su servicio en español en OC.

Radio Exterior de España no es ajena a este proceso. La dirección de RTVE ha decidido potenciar la presencia de la emisora internacional de RNE en Internet y en las redes sociales. De esta forma, REE se puede escuchar en la actualidad en España y en cualquier lugar del mundo a través de la red en todo tipo de dispositivos con acceso a Internet: ordenador, tableta o teléfonos inteligentes. Esto, unido al retroceso de los oyentes en onda corta ha llevado a la corporación RTVE a suprimir las emisiones por este medio o reducir su potencia de transmisión en Europa y Norteamérica. Se alega también para justificar esta decisión el elevado coste económico de transmitir en onda corta, algo que es cierto. Sin embargo, creo que esta decisión parte de una premisa falsa: considerar que todo el mundo tiene ADSL, cable o un iPhone para acceder a Internet y escuchar la radio. Según la UNESCO, más de 3.000 millones de personas no tienen acceso a la red de redes. Pese al avance y la pujanza de las nuevas tecnologías, hay amplios sectores de la población que no utilizan Internet en Europa y Norteamérica. Además muchas familias no pueden permitirse pagar el acceso a la red y, por supuesto, su uso está mucho menos extendido entre las personas con una edad avanzada. Se da la circunstancia de que buena parte de la audiencia de Radio Exterior de España son personas mayores que escuchan la emisora con sus transistores de onda corta.

La dirección de RTVE también alega que REE se puede sintonizar en estas zonas con radios digitales. Sin embargo, su uso no está extendido, entre otras razones, porque son receptores con un coste alto en comparación con las radios de onda corta.

La Ley 17/2006 de la radio y la televisión de titularidad estatal establece la obligación para RNE de difundir canales radiofónicos de cobertura internacional para la proyección de la lengua y la cultura española y la atención a los españoles en el extranjero. La corporación RTVE, en mi opinión, falta a su obligación al suprimir las emisiones en onda corta en algunas zonas del planeta y, lo que es peor, supone dejar en la estacada a miles de oyentes que siempre han escuchado Radio Exterior de España a través de la onda corta.

Quiero traer a colación el caso de una monja española en un convento de Roma que entró en antena para contar que era fanática del programa Tablero Deportivo que emite Radio Nacional y Radio Exterior de España. ¿Se imaginan a esta religiosa escuchando REE a través de Internet con un portátil o un teléfono de última generación? Por supuesto, yo no. Pues bien, como ella hay miles y miles de oyentes de Radio Exterior que demuestran que la onda corta sigue siendo necesaria en el siglo XXI. Esa vigencia de la onda corta es todavía mucho más importante en las emisiones de REE para Centroamérica, Sudamérica, Asia y África, y valga como ejemplo el caso de Clara Rojas, la abogada colombiana que estuvo secuestrada por la guerrilla de las FARC. Tras ser liberada, declaró que durante su cautiverio le dieron una radio con onda corta y pasaba las horas 
escuchando Españoles en la Mar, un programa de Radio Exterior de España del que me honro en formar parte. La emoción y el orgullo que los periodistas que trabajamos en este programa sentimos al escuchar esas palabras son indescriptibles. También el capitán del buque Alakrana, secuestrado durante 47 días por piratas somalíes, nos explicó cómo estuvieron al tanto de las noticias del secuestro gracias a REE que escuchaban en una radio de onda corta que lograron ocultar a sus captores.

Españoles en la Mar nació para dar servicio a los miles de españoles embarcados en buques de pesca, de la marina mercante y de la armada. Cuando los barcos se encuentran en alta mar, en la mayoría de los casos, los marineros sólo pueden acceder a la radio a través de la onda corta. Este programa ha sido, es $\mathrm{y}$, esperemos, seguirá siendo una referencia para las gentes de la mar, como nos demuestran a través de sus cartas y correos electrónicos en los que agradecen que haya un espacio dedicado a informar diariamente sobre su actividad. Para ellos, escuchar el programa y Radio Exterior de España, a través de Internet o el satélite, no es una opción en estos momentos, por su elevado coste económico.

En definitiva, en mi opinión, Internet debe ser un medio para ampliar la difusión de Radio Exterior de España en el mundo y las formas de relacionarse con su audiencia y no la excusa para la supresión de las emisiones de onda corta, cuando además su coste, aún siendo considerable, es un porcentaje muy pequeño del presupuesto global de la corporación RTVE. Al igual que la aparición de la frecuencia modulada (FM) no supuso el fin de la onda media (OM), la radio online tiene que ser una de las vías de transmisión del canal internacional de RNE, pero sin menoscabar el que ha sido uno de los pilares fundamentales para su presencia en el mundo a lo largo de sus 70 años de historia: la onda corta.

\section{Referencias}

Asociación para la Investigación de los Medios de Comunicación (AIMC) (2012). La Radio: Tradicional vs Online.

García Gago, Santiago (2010). Manual para radialistas analfatécnicos. Ecuador: Unesco.

Ley 17/2006, de 5 de junio de la Radio y la Televisión de Titularidad Estatal.

\section{Referencia de este artículo}

Fernández Cuesta, Antonio (2013). Onda corta vs. radio online. Radio Exterior de España en la era digital. En: adComunica. Revista Científica de Estrategias, Tendencias e Innovación en Comunicación, $\mathrm{n}^{\circ} 5$. Castellón: Asociación para el Desarrollo de la Comunicación adComunica, Universidad Complutense de Madrid y Universitat Jaume I, 251-254. DOI: http://dx.doi.org/10.6035/21740992.2013.5.16. 